\title{
Natural Radioactivity of Solid and Liquid Phases from Shale oil and Gas Prospecting in Pomerania
}

\author{
Anna Mykowska*, Jan Hupka \\ Department of Chemical Technology, Faculty of Chemistry, Gdańsk University of Technology, \\ Narutowicza 11/12, 80-233 Gdańsk, Poland \\ Received: 6 May 2014 \\ Accepted: 23 May 2014
}

\begin{abstract}
Ionizing radiation intensity data and estimation of equivalent absorbed doses from solid and liquid samples from prospecting shale gas and oil at select sites in Pomerania are presented. Naturally occurring radioactive materials (NORM) are associated with geological formations or fluids and can be enhanced during oil and gas production. They appear in e.g. drilling cuttings, flow-back water, produced water, scale, and sludge. In this study only gamma rays were detected and their intensity was comparable to the background radiation, which is $20.0 \pm 4.6\left[\mathrm{~min}^{-1}\right]$. The highest value of $27.3\left[\mathrm{~min}^{-1}\right]$ was detected in solid residue from evaporated flow-back fluid after hydraulic fracturing. The equivalent absorbed dose from this sample was $\sim 2 \mathrm{~Sv} / \mathrm{a}$, which is lower than the global average dose from 2.4 Sv/a background radiation. In this regard, workers and others in the vicinity of drilling well sites will not be exposed to external or internal ionizing radiation.
\end{abstract}

Keywords: naturally occurring radioactive material (NORM), natural radioactivity, oil and gas industry, gamma radiation, shale gas

\section{Introduction}

Naturally occurring radioactive materials (NORMs) present in Earth's crust are an obvious factor in the exploration of fossil energy resources. $75 \%$ of human radiation exposure results from natural resources [1]. Most of the radioactivity in rock reservoirs is associated with decay of Potassium-40, Uranium-238, and Thorium-232. These isotopes have a half-life similar to the age of the Earth and are still present in subsurface formations in parts per million concentrations besides those from the decay chain [2].

For some kinds of rocks, geological formations, and regions, the level of natural radioactivity can be higher than the global average background radiation. The sum of cosmic radiation and natural sources of radioactivity in soil, air, and water gives annual effective dose classified into four stages from low $(<5 \mathrm{mSv} / \mathrm{a})$ to high radioactive areas $(50>\mathrm{mSv} / \mathrm{a})$ [16], the most known are in Iran (Ramsar),

\footnotetext{
*e-mail: anna.mykowska@pg.gda.pl
}

India (Karunagappally in Kerala), and Brazil (e.g. Poços de Caldas, Araxa, Tapira) [3].

The annual effective dose from background radiation is $2.4 \mathrm{mSv} / \mathrm{a}$ with a typical range from 1 to $10 \mathrm{mSv} / \mathrm{a}$, but there are also areas exceeding $50 \mathrm{mSv} / \mathrm{a}$ [1]. In Poland the average dose in 2011 was $3.3 \mathrm{mSv} / \mathrm{a}$ [4]. The variability of gamma radiation in different regions corresponds to the lithology of geological formations. Daily average gamma dose rate results from terrestrial gamma radiation at the Polish Geological Institute are shown in Fig. 1., with an average dose equal to $58 \mathrm{nGy} / \mathrm{h} \mathrm{[5]}$.

Industrial operations can also cause higher concentrations of radioactive materials - in this case they are called TENORM (technologically enhanced NORM). TENORM waste or by-products are produced, for example, in phosphate processing, exploration, and production of oil and gas or geothermal energy, metal and uranium mining, and production of zircon and sulphuric acid $[6,7]$. Ionizing radiation associated with the oil and gas industry has been a widely recognized occurrence - the earliest report about 
NORM in the oil and gas industry is from 1904 [2]. Later in the 1980s elevated levels of Ra-226 were observed for the first time in an oil field pipeline [8].

\section{Mobilization of Radionuclides}

Radionuclides from hydrocarbon reservoirs are present in the solid, liquid, and gas phases. The amount of radioactive substances at the surface depends on the radioactivity in subsurface formations, the exploration and production process, and on the duration of this process or the leaching potential of the formation fluid [9]. These factors are influenced by temperature, pressure, and $\mathrm{pH}$, which leads to the mobility change of NORM - e.g. the solubility of radioactive isotopes of radium. Solubility of radium is greater in saline water for extreme $\mathrm{pH}$ value (either low or high) [10]. Thus radium precipitates as sulphate or carbonate scales which emit ionizing radiation. The scale can be observed in pipes, vessels, tanks, separators, valves, and other facilities at production sites [4].

The activity of radioisotopes Ra-226 and Th-232 in industrial solid and liquid samples is provided in Table 1. The range of radioactivity associated with oil and gas production is wide since it depends not only on the nature of the rock but also geological and geographical factors and the treatment process. For example, radon Rn-222 in gas samples is from below detection limits to over 150,000 $\left[\mathrm{Bq} / \mathrm{m}^{3}\right]$ [11], and in solid samples from 0.4 to 15,000 $[\mathrm{Bq} / \mathrm{kg}]$ [2]. Thus the concentration of NORM is variable, cannot be predicted, and should be examined in the area of oil and gas production.

The radioactivity of liquid and solid samples from shale gas and oil exploration in Pomerania is reported in this paper. The impulse to the research was the lack of information about NORM concentrations in Pomerania geological formations. Now when shale gas and oil prospecting is being conducted, it is important to check the level of natural radiation in the area.

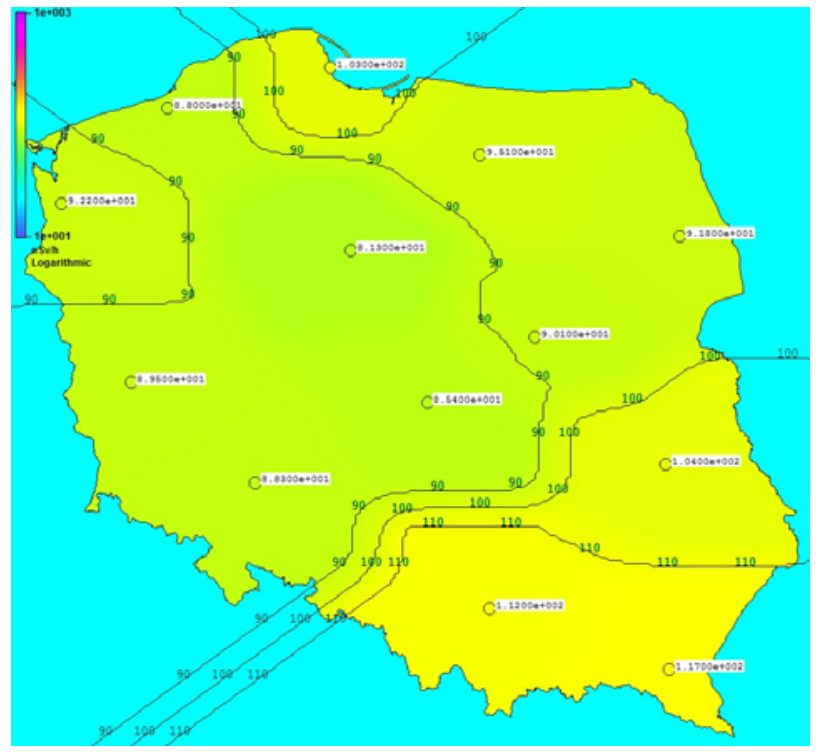

Fig. 1. Gamma dose rates in Poland [17].
Table 1. Activity of radioisotopes Ra-226 and Th-232 in select solid and liquid samples associated with oil and gas reservoirs.

\begin{tabular}{|c|c|c|c|}
\hline No. & Sample & $\begin{array}{c}\text { Counts per } \\
\text { minute }\left[\mathrm{min}^{-1}\right]\end{array}$ & $\begin{array}{c}\text { Equivalent } \\
\text { dose }[\mu \mathrm{Sv} / \mathrm{h}]\end{array}$ \\
\hline 1 & Background & 20.0 & 0.175 \\
\hline 2 & Drilling cuttings 1 & 20.3 & 0.177 \\
\hline 3 & Drilling cuttings 2 & 21.6 & 0.188 \\
\hline 4 & $\begin{array}{l}\text { Solid residue from } \\
\text { flow-back fluid }\end{array}$ & 27.3 & 0.238 \\
\hline 5 & Drilling cuttings 3 & 20.7 & 0.181 \\
\hline 6 & Pomerania A1 & 21.4 & 0.187 \\
\hline 7 & Pomerania A2 & 21.8 & 0.190 \\
\hline 8 & Pomerania C1 & 21.9 & 0.191 \\
\hline 9 & Pomerania B1 & 18.8 & 0.164 \\
\hline 10 & Pomerania B2 & 22.0 & 0.192 \\
\hline
\end{tabular}

\section{Experimental Procedure}

The locations and detailed descriptions of samples are classified as a precondition made by drilling companies. Liquid and solid samples that originated from subsurface formations were investigated: flow-back fluid (Fig. 2), residue from flow-back fluid, and drilling cuttings from two depths (Fig. 3). Drilling mud before being pumped into the borehole served as a reference sample.

Levels of natural radioactivity were measured using a portable GAMMA-SCOUT detector containing a GeigerMüller counter, one of the recommended instruments as an indicator or dosimeter by the International Association of Oil and Gas Producers in "Guidelines for the management of naturally occurring radioactive material (NORM) in the oil and gas industry" [2].

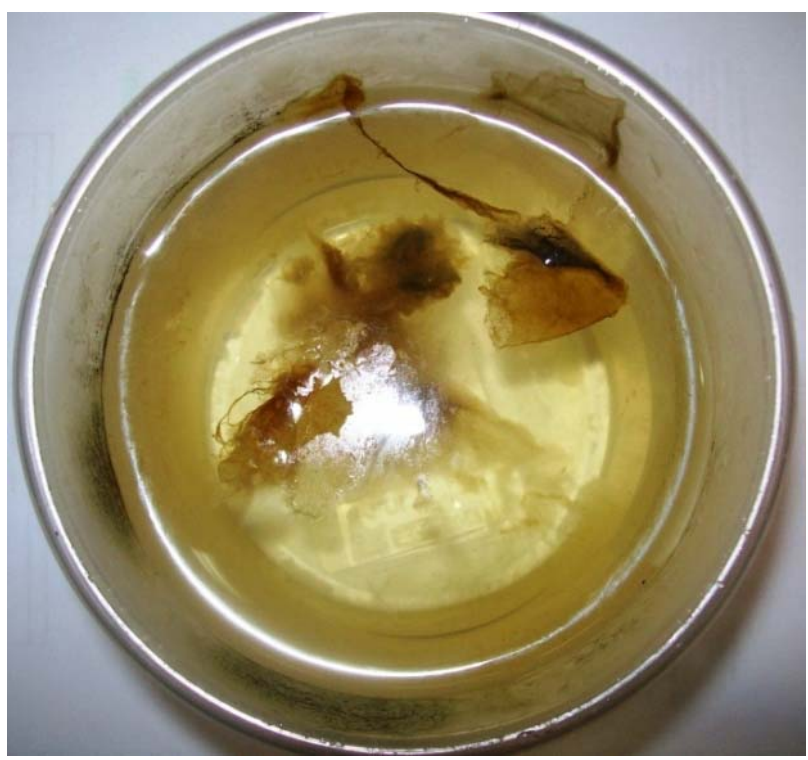

Fig. 2. Flow-back fluid. 
a)
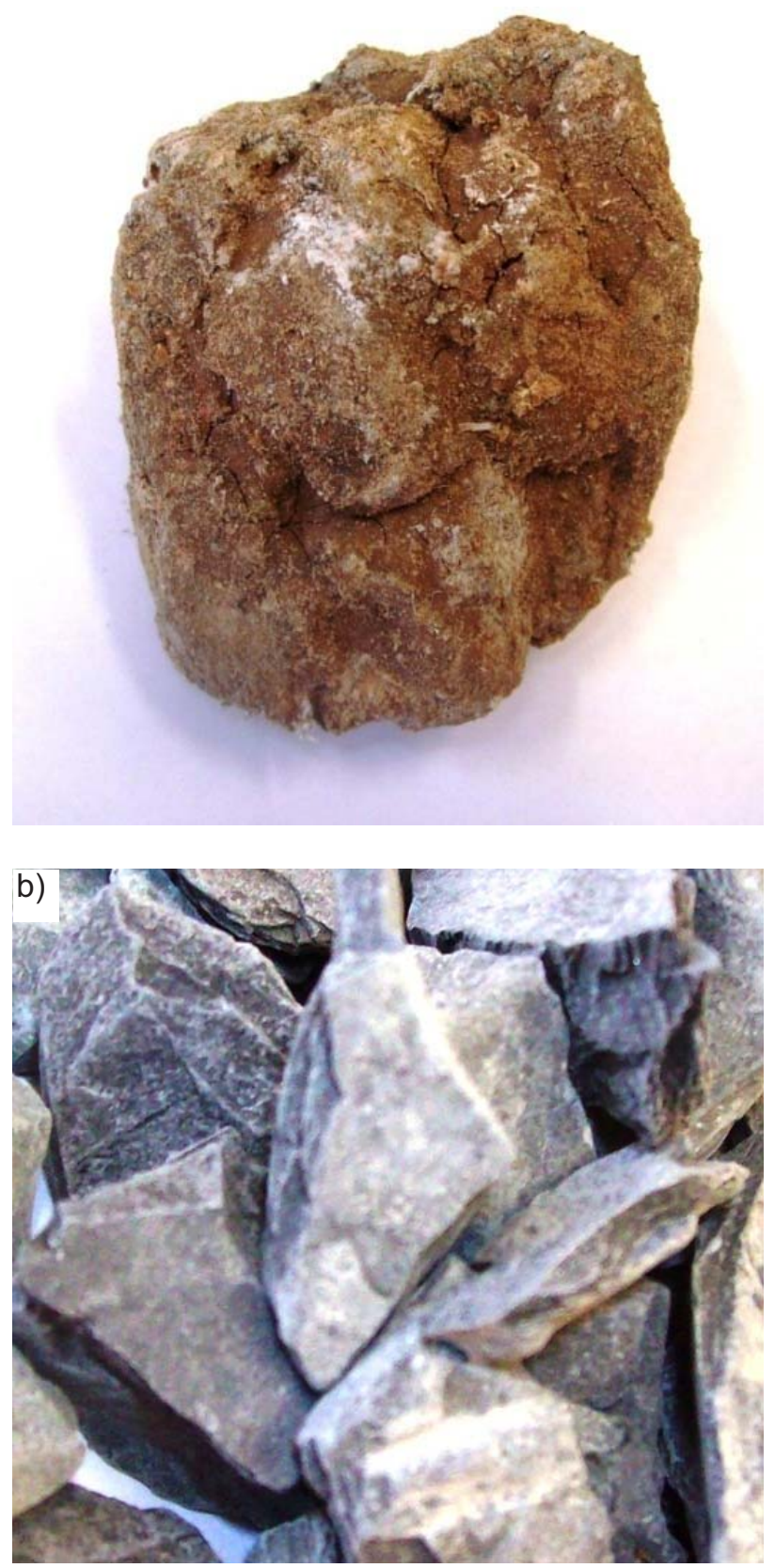

Fig. 3. Drilling cuttings. Depth $1895 \mathrm{~m}-\mathrm{a}$ ) and depth 4228.5 $\mathrm{m}$ gas-bearing shales $-\mathrm{b}$ ).
The first measurement was made to determine background radiation. It was important for the experiment to be made properly as this is the reference value, which is why it was repeated 80 times. Every sample was measured:

- 10 times for gamma radiation

- 10 times for beta and gamma radiation

- 10 times for alpha, beta, and gamma radiation.

In the first case, the radiation selection switch covered the window of the counter tube with an aluminum plate, in the second with aluminum foil, and in the third it was left open. Counts per minute (number of ionizing events) can also be approximately counted for equivalent absorbed doses according to the equation based on Cs-137:

$$
114.67 \frac{1}{\min }=1 \frac{\mu S v}{h}
$$

This is the only estimated value of gamma dose because the kind of radioisotopes that emit radiation are not known. This can be precisely calculated after calculation of acivity of radionuclides.

\section{Results}

The radiation expressed in counts per minute $\left[\mathrm{min}^{-1}\right]$ for analyzed samples is shown in Table 2 . Only gamma radiation measurements are indicated in this table since there were no alpha or beta particles that could be detected by the G-M counter. The standard deviation for all samples remained within $20-25 \%$. For the background radiation is $4.6 \mathrm{~min}^{-1}$, therefore the result is $20.0 \pm 4.6 \mathrm{~min}^{-1}$.

Comparison measurement points of analyzed samples with the average background radiation is on Fig. 4. One point is above background radiation - No. 4 solid residue from produced water with $27.3 \mathrm{~min}^{-1}$ value when the range of background radioactivity is $15.4 \mathrm{~min}^{-1}$ to $24.6 \mathrm{~min}^{-1}$.

\section{Discussion of Results}

Examined solid and liquid samples from prospection of shale oil and gas emit radiation similar to the average background counts per minute. Background radiation consists of

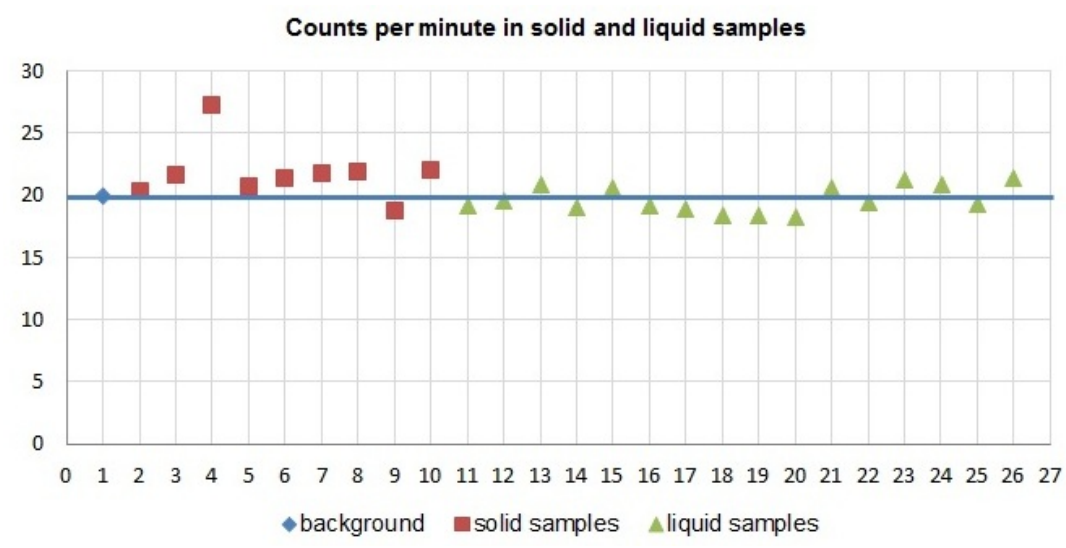

Fig. 4. Measurement points (counts per minute $\left[\mathrm{min}^{-1}\right]$ ) of analyzed samples. 
Table 2. Gamma radiation in solid samples $\left[\mathrm{min}^{-1}\right]$ and approximate equivalent absorbed dose.

\begin{tabular}{|c|c|c|c|c|c|}
\hline \multirow{2}{*}{ Sample } & \multicolumn{2}{|c|}{ Activity $[\mathrm{Bq} / \mathrm{kg}]$} & \multirow{2}{*}{ Country } & \multirow{2}{*}{ Other information } & \multirow{2}{*}{ References } \\
\hline & $\mathrm{Ra}-226$ & Th-232 & & & \\
\hline Produced water & 19.00 & 39.90 & \multirow{3}{*}{ Tunisia } & From tank & \multirow{3}{*}{12} \\
\hline Produced water & 0.37 & 0.74 & & From separator & \\
\hline Formation water & 0.04 & 0.03 & & - & \\
\hline Formation water & $5.10-14.80$ & - & Algeria & From several oil fields & \multirow{2}{*}{13} \\
\hline Formation water & 1.70 & - & Great Britain & - & \\
\hline Produced water & $0.002-1200.00$ & $<0.001$ & - & - & 14 \\
\hline Hard scale & $1-15000$ & $0.001-0.002$ & - & - & 14 \\
\hline Scale & $109.60-2110.00$ & - & Brazil & From internal surface of facilities & 15 \\
\hline Sludge & $0.05-800.00$ & $0.002-0.01$ & - & - & 14 \\
\hline Sludge & $5.00-19.00$ & $2.00-12.00$ & Libya & From facilities on several oil fields & 12 \\
\hline Clay shale & $1 \div 990$ & - & - & - & 14 \\
\hline Clay & $28.7 \pm 22.2$ & $67.1 \pm 10.0$ & Nigeria & - & 16 \\
\hline
\end{tabular}

natural radiation and radiation from synthetic sources. All of the samples except one are in the range of the average radiation, which is from $15.4\left[\mathrm{~min}^{-1}\right]$ to $24.6\left[\mathrm{~min}^{-1}\right]$. Evaporated produced water had $27.3\left[\mathrm{~min}^{-1}\right]$ activity. This corresponds to the rather low value of the equivalent absorbed dose $\sim 2 \mathrm{mSv} / \mathrm{a}$, and $2.4 \mathrm{mSv} / \mathrm{a}$, the average dose from natural global background radiation according to UNSCEAR [17]. The cause of higher activity compared to the other samples is due to concentrations of radionuclides after evaporation.

The results of the investigation of natural radioactivity from oil and gas exploration were compared to the literature. Tables 2 and 3 show activity of Pomeranian samples and Table 4 (exposure rate level in the oil industry - TENORM from oil and gas industry wastes) from the references. The comparison could be made only when the literature data had sievert [Sv] or gray [Gy] units. The concentrations of radionuclides $[\mathrm{Bq} / \mathrm{kg}]$ only without reference to sample amount does not inform about the absorbed doses or hazard of exposure.

Equivalent absorbed dose reported in references is greater than that from the analyzed samples. Radiation data from Table 4 pertains to sludge and scale in industrial production facilities, therefore they could be accumulated in extended exploration time. Pomeranian boreholes are by far only prospect drillings, thus no NORM in scale and sludge in facilities was accumulated.

\section{Conclusions}

Naturally occurring radioactive materials (NORMs) constitute an integral part of the environment. Industrial operations such as exploration of oil and gas resources can enhance the local level of radioactivity above the back- ground radiation. The impulse to this research was the lack of information about natural radioactivity and amount of NORM related to oil and gas exploration in Pomerania. Investigated solid and liquid samples from shale gas and oil prospecting in Pomerania emit radiation comparable to the

Table 3. Gamma radiation in liquid samples $\left[\mathrm{min}^{-1}\right]$ and approximate equivalent absorbed dose.

\begin{tabular}{|c|c|c|c|}
\hline No. & Sample & $\begin{array}{c}\text { Counts per } \\
\text { minute }\left[\mathrm{min}^{-1}\right]\end{array}$ & $\begin{array}{c}\text { Equivalent } \\
\text { dose }[\mu \mathrm{Sv} / \mathrm{h}]\end{array}$ \\
\hline 11 & Drilling mud & 19.2 & 0.167 \\
\hline 12 & Flow-back fluid & 19.5 & 0.17 \\
\hline 13 & Pomerania B3 & 20.9 & 0.182 \\
\hline 14 & Pomerania C2 & 19 & 0.166 \\
\hline 15 & Pomerania C3 & 20.6 & 0.18 \\
\hline 16 & Pomerania C4 & 19.2 & 0.167 \\
\hline 17 & Pomerania C2 & 18.9 & 0.165 \\
\hline 18 & Pomerania C5 & 18.4 & 0.16 \\
\hline 19 & Pomerania C6 & 18.4 & 0.16 \\
\hline 20 & Pomerania D1 & 18.2 & 0.159 \\
\hline 21 & Pomerania B4 & 20.6 & 0.18 \\
\hline 22 & Pomerania C7 & 19.4 & 0.169 \\
\hline 23 & Pomerania C8 & 21.3 & 0.186 \\
\hline 24 & Pomerania C9 & 20.9 & 0.182 \\
\hline 25 & Pomerania D2 & 19.3 & 0.168 \\
\hline 26 & Pomerania E & 21.4 & 0.187 \\
\hline
\end{tabular}


Table 4. Equivalent absorbed doses $[\mu \mathrm{Sv} / \mathrm{h}]$ in the oil industry [9].

\begin{tabular}{|c|c|c|}
\hline No. & Country & $\begin{array}{c}\text { Equivalent absorbed dose } \\
{[\mu \mathrm{Sv} / \mathrm{h}]}\end{array}$ \\
\hline 27 & Algeria & Background -100 \\
\hline 28 & United Kingdom & $100-300$ \\
\hline 29 & Egypt & $50-100$ \\
\hline 30 & Congo, Italy, Tunisia & $0,1-6$ \\
\hline 31 & USA & $<300$ \\
\hline
\end{tabular}

background, which amounts to $20.0 \mathrm{~min}^{-1}$. According to this, workers and other people in the vicinity of those sites are not exposed to external or internal ionizing radiation. The samples emitted only gamma radiation. Alpha and beta radiation were not detected by Geiger-Müller counter. Based on this experiment alone, one cannot generalize results to the Baltic Basin within Pomerania borders, to other depths, locations, and fluid chemical compositions as used in this work. In this regard, measuring sludge, scale, and investigation on drilling cuttings and produced water will be continued.

The comparison of results of analyzed samples and results reported in references (Table 4) shows that equivalent absorbed doses are higher in the literature. Measurements with G-M counter made a screening stage of elevated levels of radiation to inform about approximate equivalent absorbed doses (as a dosimeter). The second step will include the types of isotopes and their concentrations $[\mathrm{Bq} / \mathrm{kg}]$.

\section{Acknowledgements}

Financial support by the Polish National Center for Research and Development Blue Gas Program EKOŁUPKI and collaborating drilling companies are gratefully acknowledged.

\section{References}

1. Sources and effects of ionizing radiation. United Nations Scientific Committee on the Effects of Atomic Radiation. UNSCEAR 2000 Report to the United Nations General Assembly, New York, 2000.

2. International Association of Oil\&Gas Producers. Report: Guidelines for the management of Naturally Occurring Radioactive Material (NORM) in the oil \& gas industry, Report No. 412, 2008.

3. SOHRABI M. World high background natural radiation areas: Need to protect public from radiation exposure. Radiat. Meas. 50, 166, 2013.

4. Environment, Central Statistical Office, Warsaw, 2012 [In Polish].

5. LIS J., PASIECZNA A., STRZELECKI R,. WOLKOWICZ S., LEWANDOWSKI P. Geochemical and radioactivity mapping in Poland. J. Geo. Exp. 60, 39, 1997.

6. ABO-ELMAGD M., SOLIMAN H.A, SALMAN KH.A., EL-MASRY N.M. Radiological hazards of TENORM in wasted petroleum pipes. J. Environ. Radioactiv. 101, 51, 2010.

7. Nuclear Safety and Radiation Protection, Public Information Bulletin of the National Atomic Energy Agency. 37, (1), 17, 1999 [In Polish].

8. LANDSBERGER S., BRABEC C., CANION B., HASHEM J., LU C., MILLSAP D., GEORGE G. Determination of ${ }^{226} \mathrm{Ra},{ }^{228} \mathrm{Ra}$ and ${ }^{210} \mathrm{~Pb}$ in NORM products from oil and gas exploration: Problems in activity underestimation due to the presence of metals and self-absorption of photons. J. Environ. Radioactiv. 125, 23, 2013.

9. ATTALLAH M.F., AWWAD N.S., ALY H.F. Environmental Radioactivity of TE-NORM Waste Produced from Petroleum Industry in Egypt: Review on Characterization and Treatment, Chapter 4 Natural Gas - Extraction to End Use, 2012.

10. SMITH K.P. An Overview of Naturally Occurring Radioactive Materials (NORM) in Petroleum Industry, Argonne National Laboratory, 1992.

11. AL-MASRI M.S., SHWIEKANI R. Radon gas distribution in natural gas processing facilities and workplace air environment. J. Environ. Radioactiv. 99, 574, 2008.

12. HRICHI H., BACCOUCHE S., BELGAIDED J. Evaluation of radiological impacts of tenorm in the Tunisian petroleum industry. J. Environ. Radioactiv. 115, 107, 2013.

$\square$ background
$\square$ drilling mud
$\square$ drilling cuttings 1
$\square$ drilling cuttings 2
$\square$ solid residue from produced water
$\square$ produced water

Fig. 5. Comparison of select analyzed samples $\left[\mathrm{min}^{-1}\right]$.

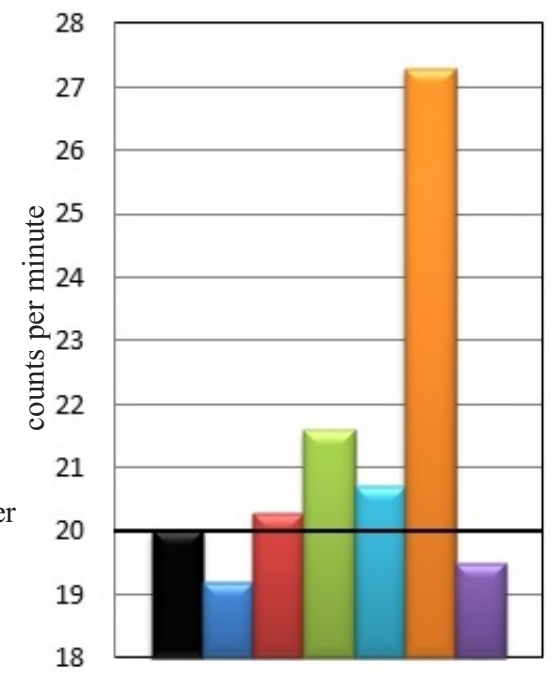


13. HAMLAT M.S., DJEFFAL S., KADI H. Assessment of radiation exposures from naturally occurring radioactive materials in the oil and gas industry. Appl. Radiat. Isotopes 55, 141, 2001.

14. International Atomic Energy Agency. Report: Radiation protection and the management of radioactive waste in the oil and gas industry, pp. 103-120, 2010.

15. PARANHOS GAZINEUA M., ARRUDA DE ARAUJO A., BATISTA BRANDAO A., ABRAHAO HAZIN C., GODOY J.M. Radioactivity concentration in liquid and solid phases of scale and sludge generated in the petroleum industry. J. Environ. Radioactiv. 81, 47, 2005.

16. OSHUA E.O., ADEMOLA J.A., AKPANOWO M.A., OYEBANJO O.A, OLORODE D.O. Natural radionuclides and hazards of rock samples collected from Southeastern Nigeria. Radiat. Meas. 44, 401, 2009.

17. Gamma dose rate in Poland http://www.paa.gov.pl/ocena-sytuacji-radiacyjnej-kraju/ rozklad-mocy-dawki-promieniowania-gamma [Online 18.12.2013], [In Polish]. 